\title{
Provision of antigen and CD137 signaling breaks immunological ignorance, promoting regression of poorly immunogenic tumors
}

\author{
Ryan A. Wilcox, ${ }^{1}$ Dallas B. Flies, ${ }^{1}$ Gefeng Zhu, ${ }^{1}$ Aaron J. Johnson, ${ }^{1}$ Koji Tamada, ${ }^{1}$ \\ Andrei I. Chapoval, ${ }^{1}$ Scott E. Strome, ${ }^{2}$ Larry R. Pease, ${ }^{1}$ and Lieping Chen ${ }^{1,3}$ \\ ${ }^{1}$ Department of Immunology, and \\ ${ }^{2}$ Department of Otorhinolaryngology, Mayo Clinic, Rochester, Minnesota, USA \\ ${ }^{3}$ International Cancer Institute and Eastern Hospital of Hepatobiliary Surgery, Shanghai, China \\ Address correspondence to: Lieping Chen, Department of Immunology, Mayo Clinic, 200 First Street Southwest, Rochester, \\ Minnesota 55905, USA. Phone: (507) 538-0013; Fax: (507) 284-1637; E-mail: chen.lieping@mayo.edu.
}

Received for publication September 10, 2001, and accepted in revised form January 14, 2002.

Treatment of advanced, poorly immunogenic tumors in animal models, considered the closest simulation available thus far for conditions observed in cancer patients, remains a major challenge for cancer immunotherapy. We reported previously that established tumors in mice receiving an agonistic $\mathrm{mAb}$ to the $\mathrm{T}$ cell costimulatory molecule 4-1BB (CD137) regress due to enhanced tumor antigen-specific cytotoxic $\mathrm{T}$ lymphocyte responses. In this study, we demonstrate that several poorly immunogenic tumors, including C3 tumor, TC-1 lung carcinoma, and B16-F10 melanoma, once established as solid tumors or metastases, are refractory to treatment by anti-4-1BB mAb. We provide evidence that immunological ignorance, rather than anergy or deletion, of tumor antigen-specific CTLs during the progressive growth of tumors prevents costimulation by anti-4-1BB mAb. Breaking CTL ignorance by immunization with a tumor antigen-derived peptide, although insufficient to stimulate a curative CTL response, is necessary for anti-4-1BB mAb to induce a CTL response leading to the regression of established tumors. Our results suggest a new approach for immunotherapy of human cancers.

J. Clin. Invest. 109:651-659 (2002). DOI:10.1172/JCI200214184.

\section{Introduction}

$4-1 \mathrm{BB}(\mathrm{CD} 137)$ is an inducible $\mathrm{T}$ cell molecule belonging to the TNF receptor superfamily $(1,2)$. It has been shown that signaling through 4-1BB by either its natural ligand, 4-1BBL, or by agonistic Ab's costimulates activation of $\mathrm{CD}^{+}$and $\mathrm{CD} 8^{+} \mathrm{T}$ cells in a CD28-independent fashion, leading to activation of the NF- $\mathrm{kB}, \mathrm{c}-J u n$ $\mathrm{NH}_{2}$-terminal kinase/stress-activated protein kinase (JNK/SAPK), and p38 signaling pathways (3-7). Expression of $4-1 \mathrm{BB}$ is also found on activated murine natural killer (NK) cells, and the ligation of monocyte-associated 4-1BB enhances monocyte activation and cytokine secretion $(8,9)$. In addition to its role in promoting the expansion of antigen-specific $\mathrm{T}$ cells, $4-1 \mathrm{BB}$ signaling may also prevent activation-induced death of $\mathrm{CD}^{+} \mathrm{T}$ cells $(10,11)$. Studies performed in 4-1BBL-deficient (4-1BBL $\left.L^{-/-}\right)$mice have demonstrated the importance of 4-1BB signaling in the generation of a fully competent cell-mediated immune response. Although $4-1 B B L^{-/}$ mice were capable of generating a cytotoxic $T$ lymphocyte (CTL) response and eliminating an acute lymphocytic choriomeningitis virus infection, expansion of $\mathrm{CD}^{+} \mathrm{T}$ cells was significantly reduced in these mice (12). Similarly, 4-1BBL ${ }^{-/-}$mice exhibited a poor CTL response to influenza virus, and analysis of antigen-specific T cells following peptide vaccination revealed a three- to tenfold reduction in the CTL response compared with that of wild-type mice $(13,14)$. Taken together, these results suggest a critical role for costimulation by $4-1 \mathrm{BB}$ in the expansion and differentiation of CTLs.

Given the importance of 4-1BB in the regulation of the immune response, the manipulation of the 4-1BB pathway represents a promising therapeutic approach. For instance, the systemic administration of an agonistic $\mathrm{mAb}$ against $4-1 \mathrm{BB}$ enhanced the $\mathrm{CD}^{+} \mathrm{T}$ cell response, leading to the eradication of established AG104A sarcomas and P815 mastocytomas in vivo (15). Furthermore, 4-1BB costimulation can synergize with B7-1 costimulation to further enhance immune responses against several poorly immunogenic tumors transfected with both costimulatory molecules $(16,17)$. Enhancement of 4-1BB costimulation (using either anti-4-1BB mAb or 4-1BBL gene transfer) with IL-12 greatly amplifies both CTL- and NK cell-mediated immune responses and leads to the complete regression of established MCA26 colon cancer in a hepatic metastasis model $(18,19)$.

Despite the ability of anti-4-1BB mAb treatment to enhance an ongoing $T$ cell response and mediate the regression of selected murine tumors, we have identified several poorly immunogenic tumors that are resistant to such treatment. In this report, we investigate the mechanisms of this resistance and demonstrate that immunological ignorance, but not anergy or deletion, 
of tumor antigen-specific CTLs prevents costimulation by anti-4-1BB mAb. Based on this finding, we developed a new approach for the treatment of established, poorly immunogenic tumors.

\section{Methods}

Tumor models and peptides. C3 cells, generated from HPV16- and EJras-transformed B6 mouse embryo cells (20), were a gift from W. Martin Kast (Loyola University, Chicago, Illinois, USA). The HPV-16 E7-transfected EL4 lymphoma line EL4E7 (21) was a gift from Germain J.P. Fernando (University of Queensland, Brisbane, Australia). The TC-1 cell line (22) was a gift from T.C. Wu (Johns Hopkins University, Baltimore, Maryland, USA), and the B16-F10 melanoma line (23) was a gift from Glenn Dranoff (Dana-Farber Cancer Institute, Boston, Massachusetts, USA). The EL4, RMA-S, and S49.1 murine $\mathrm{T}$ cell lymphoma cells were of B6 origin and were purchased from American Type Culture Collection (Rockville, Maryland, USA). All cell lines were maintained in a complete medium of RPMI 1640 (Life Technologies Inc., Gaithersburg, Maryland, USA) supplemented with 10\% FBS (HyClone Laboratories, Logan, Utah, USA), 25 mM HEPES, 2 mM glutamine, 100 $\mathrm{U} / \mathrm{ml}$ penicillin $\mathrm{G}$, and $100 \mu \mathrm{g} / \mathrm{ml}$ streptomycin sulfate. The E7 peptide (aa 49-57) (RAHYNIVTF) used comprises the minimal H-2 $\mathrm{D}^{\mathrm{b}}$-restricted CTL epitope (20) of the HPV-16 E7 protein. The TRP-2 peptide (SVYDFFVWL) is an $\mathrm{H}-2 \mathrm{~K}^{\mathrm{b}}$-restricted epitope first identified in the B16 melanoma $(24,25)$. The Vp2 control peptide (FHAGSLLVFM) contains an H-2D ${ }^{\mathrm{b}}$-restricted CTL epitope derived from Theiler's murine encephalomyelitis virus (26). The OVA (aa 257-264) control peptide (SIINFEKL) is an $\mathrm{H}-2 \mathrm{~K}^{\mathrm{b}}$-restricted CTL epitope derived from chicken ovalbumin $(27,28)$. All peptides were synthesized by the Mayo Clinic Molecular Biology Core Facility. The purity of each peptide was greater than $95 \%$, as confirmed by reverse-phase HPLC purification.

Female C57B6 mice were purchased from the National Cancer Institute (Frederick, Maryland, USA). Agematched mice, 6-10 weeks old, were used for all experiments. Tumor cells in $0.1 \mathrm{ml}$ of PBS were injected intradermally into the shaved right flank of each mouse. Mice were given either $1 \times 10^{6} \mathrm{C} 3$ cells or $4 \times 10^{6}$ EL4E7 cells. Tumor size (the average of two perpendicular diameters, in $\mathrm{mm}$ ) was measured weekly as previously described (29). For lung metastasis models, $1 \times 10^{4} \mathrm{TC}-1$ or $1 \times 10^{5} \mathrm{~B} 16-\mathrm{F} 10$ cells in $0.5 \mathrm{ml} \mathrm{HBSS}$ were injected into the tail vein of mice. Mice bearing subcutaneous tumors were immunized intradermally with $50 \mu \mathrm{g}$ of peptide emulsified in incomplete Freund's adjuvant at a site contralateral to the tumor (Sigma Chemical Co., St. Louis, Missouri, USA). Mice bearing lung metastases were immunized bilaterally intradermally with a total of $100 \mu \mathrm{g}$ of peptide emulsified in IFA. Ab's administered to mice were given intraperitoneally in $0.5 \mathrm{ml}$ of PBS.

$A b$ 's, tetramers, and fusion protein. To prepare the 4-1BB-Ig fusion protein, the extracellular domain of mouse 4-1BB was amplified from activated spleen cell cDNA using sequence-specific primers. It was fused to the $\mathrm{CH}_{2}-\mathrm{CH}_{3}$ domain of mouse IgG2a in expression plasmid pmIgV (30) and was transfected into $\mathrm{CHO}$ cells. The protein in the culture supernatants was purified using a HiTrap protein G-Sepharose column (Amersham Pharmacia Biotech, Piscataway, New Jersey, USA) and dialyzed in LPS-free PBS.

$A$ rat $m A b$ against $4-1 B B$ was generated by immunizing a Lewis rat (Harlan Sprague Dawley Inc., Indianapolis, Indiana, USA) with mouse 4-1BB-Ig. Hybridomas were produced by fusing rat spleen cells with mouse Sp2/0 myeloma cells. The culture supernatants were screened by ELISA, and the hybridoma secreting $\mathrm{mAb} 2 \mathrm{~A}$ was selected for further experiments. Hybridoma 2A was grown in RPMI 1640 supplemented with $10 \%$ low-IgG FBS (Life Technologies Inc.) and 25 mM HEPES. Supernatant was harvested, concentrated using a tangential flow miniplate concentrator (Millipore Corp., Bedford, Massachusetts, USA), and purified using a 5-ml HiTrap protein G-Sepharose column. Purified mAb's were dialyzed against PBS and concentrated using a Centriprep Centrifugal Filter Device (Millipore Corp.). The mAb was isotyped using biotinylated, isotype-specific Abs (Caltag Laboratories, Burlingame, California, USA).

Purified mAb's against mouse CD3, CD28, and 4-1BB, and the FITC-CD8 mAb were purchased from PharMingen (San Diego, California, USA). The FITC-conjugated goat anti-rat $\mathrm{Ab}$ was purchased from BioSource International (Camarillo, California, USA). Rat IgG Ab's (Sigma Chemical Co.) were used as controls. The depleting $\mathrm{mAb}$ against CD4 (GK1.5) was a generous gift from David McKean (Mayo Clinic). The depleting mAb against NK1.1 (PK136) was obtained from American Type Culture Collection. For depletion experiments, $200 \mu \mathrm{g}$ of the appropriate mAb was injected intraperitoneally 48 hours and 72 hours prior to treatment and every 3-4 days thereafter, for the duration of the experiment. Depletion of the appropriate cell subset was confirmed by FACS analysis (Becton Dickinson Immunocytometry Systems, Mountain View, California, USA).

The $\mathrm{H}-2 \mathrm{D}^{\mathrm{b}}-\mathrm{E} 7$ and $\mathrm{H}-2 \mathrm{D}^{\mathrm{b}}-\mathrm{V} \mathrm{p} 2$ tetramers were prepared as previously described (26). Briefly, H-2D $\mathrm{D}^{\mathrm{b}}$ and human $\beta_{2}$-microglobulin were isolated from a bacterial expression system and subsequently folded in an excess of peptide. The folded monomeric complexes were desalted and biotinylated. Following cation exchange purification, the monomeric complexes were conjugated with R-phycoerythrin-streptavidin, forming a tetrameric complex. The $\mathrm{H}-2 \mathrm{D}^{\mathrm{b}}$ tetramers generated were purified by size-exclusion gel filtration.

$T$ cell costimulation assay. The method for the mAb costimulatory function assay was described previously (29). Briefly, nylon wool-purified splenic T cells $\left(2.5 \times 10^{6} / \mathrm{ml}\right)$ were added to 96-well plates coated with an $\mathrm{mAb}$ against CD3 $(0.1 \mu \mathrm{g} / \mathrm{ml})$ and the indicated concentrations of rat IgG or mAb 2A. Proliferation of T cells was assessed by the addition of $1 \mu \mathrm{Ci} /$ well $^{3} \mathrm{H}$-tritium deoxyribonucleotide 

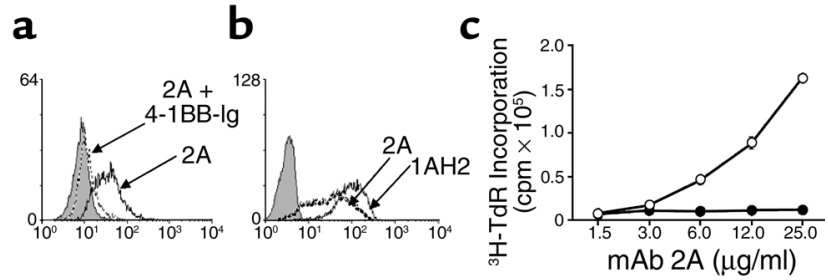

Figure 1

$\mathrm{mAb} 2 \mathrm{~A}$ binds murine 4-1BB and costimulates $T$ cell growth in vitro. (a) Nylon wool-purified T cells stimulated for 24 hours in the presence of plate-bound anti-CD3 and anti-CD28. Cells were stained with $\mathrm{mAb} 2 \mathrm{~A}$ or an isotype control (shaded region), both in the presence and absence of 4-1BB-Ig. (b) Cultured S49.1 murine T lymphoma cells were stained with $\mathrm{mAb} 2 \mathrm{~A}$ or a commercially available mAb against 4-1BB (clone 1AH2; PharMingen). (c) Nylon wool-purified $T$ cells were stimulated with a suboptimal dose of plate-bound anti-CD3 $(0.1 \mu \mathrm{g} / \mathrm{ml})$ and the indicated concentrations of platebound rat IgG (filled circles) or mAb $2 \mathrm{~A}$ (open circles). ${ }^{3} \mathrm{H}-\mathrm{TdR}$, ${ }^{3} \mathrm{H}$-tritium deoxyribonucleotide.

during the last 15 hours of the 3 -day culture. ${ }^{3} \mathrm{H}$-tritium deoxyribonucleotide incorporation was measured in a MicroBeta TriLux liquid scintillation counter (Wallac, Turku, Finland).

FACS analysis. T cells were positively selected with FITC-conjugated mAb's against CD4 and CD8 using anti-FITC microbeads in the magnetic field of MACS magnetic separator, as instructed by the manufacturer (Miltenyi Biotec, Auburn, California, USA). The purity of the isolated $\mathrm{T}$ cells was greater than $95 \%$, as assessed by flow cytometry using an $\mathrm{mAb}$ against CD3. Purified $\mathrm{T}$ cells $\left(2.5 \times 10^{6}\right.$ cells $\left./ \mathrm{ml}\right)$ from mouse spleens were stimulated in 24-well plates coated with mAb's against CD3 $(5 \mu \mathrm{g} / \mathrm{ml})$ and CD28 $(1 \mu \mathrm{g} / \mathrm{ml})$. After 24 hours, T cells were collected and then stained for 30 minutes at $4^{\circ} \mathrm{C}$, with $1 \mu \mathrm{g} \mathrm{mAb} 2 \mathrm{~A}$ alone or $1 \mu \mathrm{g} \mathrm{mAb} 2 \mathrm{~A}$ in the presence of $4-1 \mathrm{BB}-\operatorname{Ig}(2 \mu \mathrm{g} / \mathrm{ml})$, in $50 \mu \mathrm{l}$ PBS supplemented with $3 \% \mathrm{FBS}$ and $0.02 \%$ sodium azide. The cells were washed and incubated for an additional $30 \mathrm{~min}-$ utes at $4{ }^{\circ} \mathrm{C}$ with FITC-conjugated goat $\mathrm{Ab}$ against rat IgG. After washing, cells were fixed in $1 \%$ paraformaldehyde, and fluorescence was analyzed by FACS (Becton Dickinson Immunocytometry Systems). S49.1 cells were stained in a similar fashion. In brief, $1 \times 10^{6} \mathrm{~S} 49.1$ cells were stained with either $\mathrm{mAb} 2 \mathrm{~A}$ or the $\mathrm{mAb}$ against 4-1BB (clone 1AH2; PharMingen). After washing, cells were stained with an FITC-conjugated goat $\mathrm{Ab}$ against rat IgG, then washed, fixed, and analyzed.

Tumor-draining lymph nodes (TDLNs) from immunized mice were harvested on day 7 and stained with phycoerythrin-conjugated $\mathrm{H}-2 \mathrm{D}^{\mathrm{b}}-\mathrm{E} 7$ or $\mathrm{H}-2 \mathrm{D}^{\mathrm{b}}-\mathrm{V}^{2} 2$ tetrameric complexes and FITC-conjugated CD8, as previously described $(26)$. TDLN cells $\left(5 \times 10^{6}\right)$ were incubated with $2.5 \times 10^{5} \mathrm{UV}$-irradiated C3 cells for 4 days. Cells were subsequently stained with the phycoerythrin-conjugated tetramers and FITC-conjugated CD8. After extensive washing, cells were resuspended in PBS with $750 \mathrm{ng} / \mathrm{ml}$ propidium iodide. Gates were drawn to include viable $\mathrm{CD}^{+}$cells.
Assay of CTL activity. CTL activity was measured using a standard 4-hour ${ }^{51} \mathrm{Cr}$ release assay with tumor cell targets at the indicated effector/target ratios. Peptidepulsed target cells were generated by adding $10 \mu \mathrm{g} / \mathrm{ml}$ of peptide and incubating at $28^{\circ} \mathrm{C}$ for 18 hours. Effector cells were obtained by coculturing draining LN cells with irradiated C3 cells as described above.

\section{Results}

Characterization of anti-4-1BB $m A b 2 A$ and its antitumor effect against EL4E7 lymphoma and C3 tumor. The specificity of anti-4-1BB mAb 2A was examined first. mAb $2 \mathrm{~A}$ stained more than $80 \%$ of purified $T$ cells, which had been activated for 24 hours by anti-CD3 and anti-CD28 mAb's. Binding was specific, since $\mathrm{Ab}$ binding could be competitively inhibited by inclusion of mouse 4-1BB-Ig (Figure 1a), whereas inclusion of a control rat IgG did not inhibit binding (data not shown). Furthermore, mAb 2A binds specifically to the mouse $\mathrm{T}$ cell lymphoma line S49.1, which constitutively expresses 4-1BB, as demonstrated by staining with $1 \mathrm{AH} 2$, a commercially available anti-4-1BB $\mathrm{mAb}$ (Figure $1 \mathrm{~b}) . \mathrm{mAb} 2 \mathrm{~A}$ was also capable of detecting 4-1BB, in a fashion identical to $1 \mathrm{AH} 2$, by Western blot of immunoprecipitates obtained from activated $T$ cells (data not shown). Immobilized $\mathrm{mAb} 2 \mathrm{~A}$ also enhanced $\mathrm{T}$ cell proliferation in a dose-dependent fashion in the presence of a suboptimal dose of anti-CD3 mAb (Figure 1c). Therefore, $2 \mathrm{~A}$ is a costimulatory $\mathrm{mAb}$ similar to others previously described $(15,31)$.
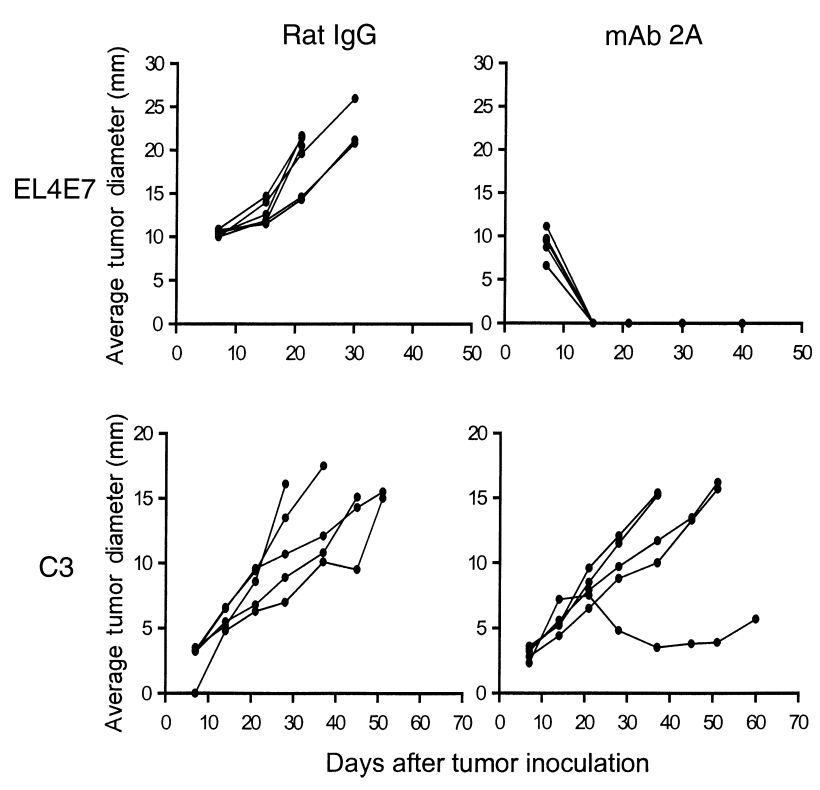

\section{Figure 2}

Treatment of established EL4E7 and C3 tumors with mAb 2A. Mice were injected subcutaneously with $1 \times 10^{6} \mathrm{C} 3$ cells (bottom panel) or $4 \times 10^{6}$ EL4E7 cells (top panel). Seven and ten days later, mice were given $100 \mu \mathrm{g}$ of either control rat IgG (left) or mAb 2A (right). Tumor size was assessed weekly and is reported as the average of two perpendicular diameters. Tumors that were no longer palpable were considered to have regressed. Each experiment is representative of at least three similarly performed experiments. 


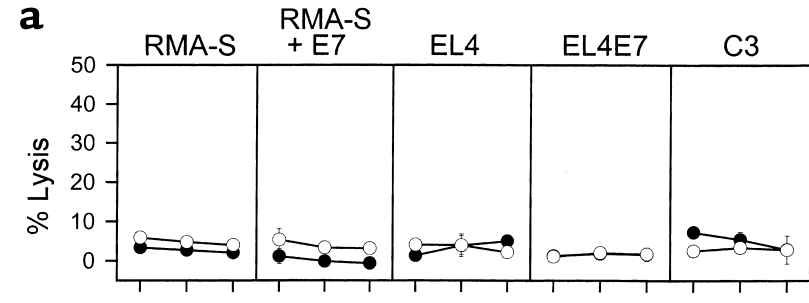

E/T ratio: $100 \begin{array}{llllllllllllll}50 & 25 & 100 & 50 & 25 & 100 & 50 & 25 & 100 & 50 & 25 & 100 & 50 & 25\end{array}$
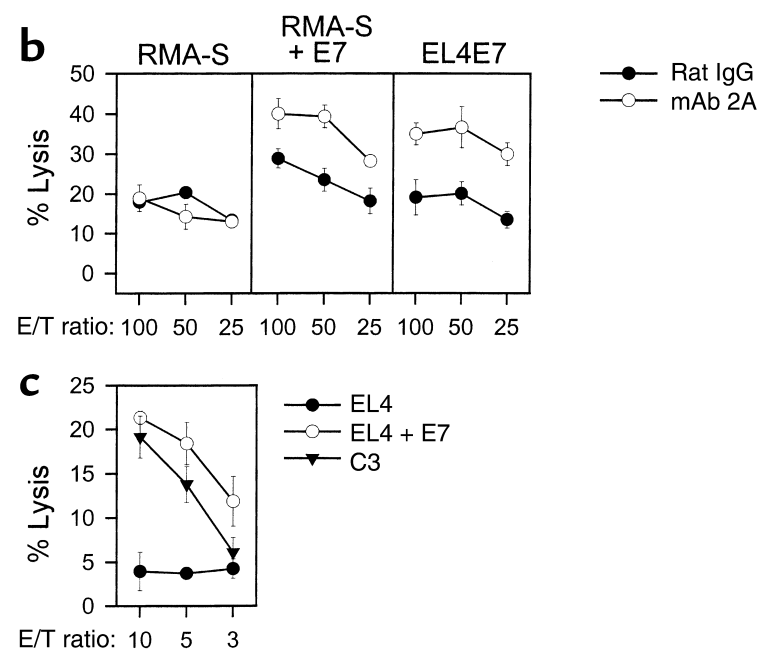

\section{Figure 3}

Cytolytic activity of tumor-specific CTLs in the TDLNs of C3- and EL4E7-bearing mice. Mice were injected subcutaneously with $1 \times 10^{6}$ C 3 cells or $4 \times 10^{6}$ EL4E7 cells on day 0 . On days 1 and 4 they were administered $100 \mu \mathrm{g}$ of either control rat IgG or mAb 2A. Seven days later, TDLNs were harvested and restimulated in vitro with irradiated C3 or EL4E7 cells for 4 days. After 4 days in culture, cells were used as effectors in a 4-hour ${ }^{51} \mathrm{Cr}$ release assay against EL4, EL4E7, RMA-S, E7 peptide-pulsed RMA-S, or C3 target cells at the indicated effector/target $(E / T)$ ratios. Effectors were generated from both C3-draining LNs (a) and EL4E7-draining LNs (b) of mice treated with the control rat IgG (filled circles) or mAb 2A (open circles). TDLNs from two to three mice were pooled in each of the experiments. Data shown are representative of three experiments. (c) An E7-specific CTL line generated by repeated in vitro stimulation of $L N$ cells from an $E 7$ peptide-immunized B6 mouse was used as the effector in a 4-hour ${ }^{51} \mathrm{Cr}$ release assay against EL4 cells, E7 peptide-pulsed EL4 cells, or $\mathrm{C} 3$ target cells at the indicated $\mathrm{E} / \mathrm{T}$ ratios.

To test whether $\mathrm{mAb} 2 \mathrm{~A}$ induces the regression of established tumors, as previously shown for other mAb's (15), two mouse tumors were selected. EL4E7 is a thymoma transfected to express the HPV-16 E7 gene (21), and C3 is an embryonic epithelial cell line transformed with HPV-16 and the ras oncogene (20). Since both tumor lines express the E7 gene of HPV-16, CTL response to the $\mathrm{E} 7$ gene product can be monitored. To determine the antitumor effect of $\mathrm{mAb} 2 \mathrm{~A}$, groups of mice bearing established EL4E7 or C3 tumors were injected intraperitoneally with $\mathrm{mAb} 2 \mathrm{~A}(100 \mu \mathrm{g})$ on day 7 and day 10. As shown in Figure 2, established EL4E7 tumors regressed rapidly in the mice injected with $\mathrm{mAb} 2 \mathrm{~A}$, whereas tumors grew progressively in the mice treated with a control rat IgG (Figure 2). Remarkably, EL4E7 tumors up to $12 \mathrm{~mm}$ in diameter regressed within 7 days following treatment. In sharp contrast, treatment of mice bearing C 3 tumors less than $4 \mathrm{~mm}$ in diameter had only a marginal effect. As shown in a representative experiment (Figure 2), retardation of tumor growth occurred in one of five mice, whereas the other tumors grew progressively. Our results indicate that, although anti-4-1BB mAb eradicates established EL4E7 tumors, C3 tumors do not respond to this treatment. It is unlikely that this resistance is due to the size of the tumor or to any antigenic disparity between the tumors.

Existence of ignorant CTLs to the $E 7$ antigen in C3-bearing mice is associated with resistance to $m A b 2 A$ treatment. To understand the mechanisms underlying the resistance to $\mathrm{mAb} 2 \mathrm{~A}$ treatment, we first examined the activation status of tumor-specific CTLs in mice bearing C3 tumors. Mice were inoculated subcutaneously with live $\mathrm{C} 3$ cells and subsequently treated with $\mathrm{mAb} 2 \mathrm{~A}$ or control rat IgG. Seven days later, the TDLNs were harvested, then restimulated in vitro with irradiated C3 cells. $\mathrm{CTL}$ activity was tested in a standard ${ }^{51} \mathrm{Cr}$ release assay. As shown in Figure 3a, neither EL4E7 cells nor C3 cells were lysed by the TDLNs in C3-bearing mice, even after treatment by $\mathrm{mAb} 2 \mathrm{~A}$. In order to ensure that $\mathrm{C} 3$ was a sensitive target, $\mathrm{T}$ cells from an E7-specific CTL line were used as effectors in a ${ }^{51} \mathrm{Cr}$ release assay. As shown in Figure 3c, C3 cells could be lysed by the E7-specific CTLs, thus demonstrating their sensitivity to CTL killing. Furthermore, CTL activity could not even be detected against RMA-S cells pulsed with the E7 peptide or against EL4E7 cells, both of which are highly sensitive target cells (see ref. 32 and Wilcox et al., unpublished data). In sharp contrast, we can reproducibly detect E7-specific CTL activity in TDLNs isolated from EL4E7-bearing mice. Furthermore, the E7-specific CTL activity could be further enhanced by treatment with $\mathrm{mAb} 2 \mathrm{~A}$ (Figure $3 \mathrm{~b}$ ). What would appear to be nonspecific lysis of the wild-type RMA-S cells in this assay may be explained by the recent observation that EL4 and RMA cells share a common tumor antigen (32).

The frequency of $\mathrm{T}$ cells specific for E7 in C3 TDLNs was determined by double staining with anti-CD8 $\mathrm{mAb}$ and an E7 tetramer. Consistent with CTL activity, less than $0.1 \%$ of $\mathrm{CD}^{+} \mathrm{T}$ cells in TDLNs from C3-bearing mice were E7-specific, even after in vitro restimulation with irradiated C3 cells. This number represents the detectable background of naive $\mathrm{T}$ cells in our assay, since similar results were obtained using cells from naive mice. Furthermore, treatment by $\mathrm{mAb} 2 \mathrm{~A}$ failed to expand E7-specific CTLs in C3 TDLNs (Figure 4, a and b). In contrast, about $1 \%$ of $\mathrm{CD}^{+}$cells were E7-specific in the EL4E7 TDLNs of mice treated with the control $\mathrm{Ab}$ after restimulation with irradiated $\mathrm{C} 3$ cells. Treatment by $\mathrm{mAb} 2 \mathrm{~A}$ in vivo promoted the expansion of specific CTLs, as demonstrated by a fourfold increase in the frequency of E7-specific T cells (Figure $4 \mathrm{~b})$. The frequency of E7-specific CTLs thus appears to correlate with CTL activity. More importantly, our results indicate that the physical absence, rather than 
a

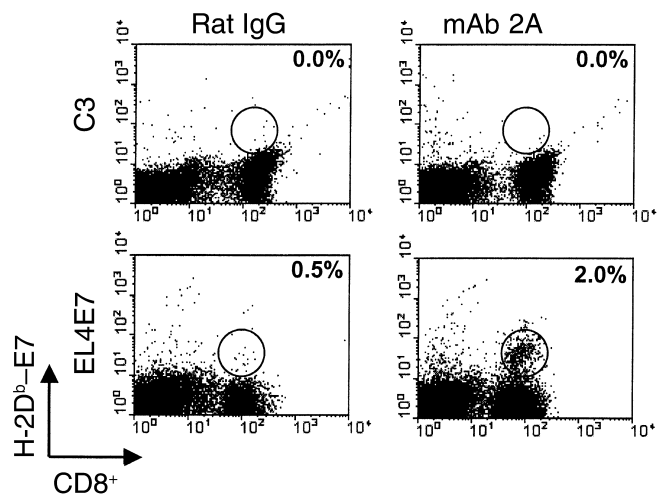

b

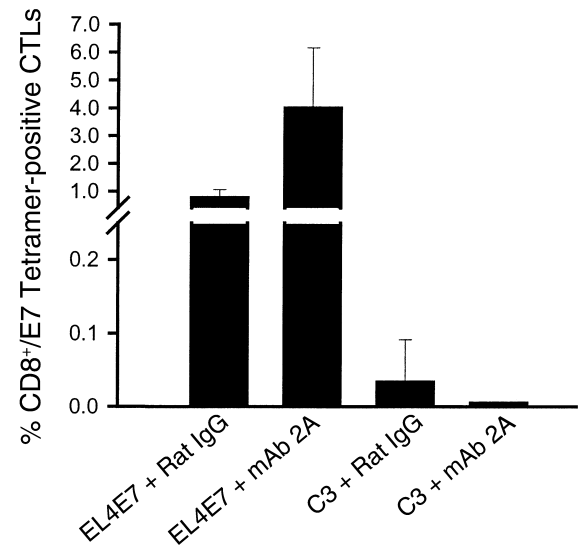

suppressed cytolytic activity, of specific CTLs in C3 TDLNs is responsible for the inability of $\mathrm{mAb} 2 \mathrm{~A}$ to boost $\mathrm{T}$ cell responses.

To exclude the possibility that E7-specific CTLs are deleted in C3 tumor-bearing mice, we examined E7specific CTL activity in C3-bearing mice after immunization with the E7 peptide containing an $\mathrm{H}-2 \mathrm{D}^{\mathrm{b}}$ restricted CTL epitope (20). Seven days after the peptide immunization, draining LNs were harvested and then restimulated with irradiated C3 cells or EL4E7 cells. The frequency of E7-specific $\mathrm{CD}^{+} \mathrm{T}$ cells was determined using the $\mathrm{E} 7$ tetramer. Immunization with E7 peptide induced a significant increase in the E7 tetramer-positive cells, whereas such cells were not

\section{Figure 5}

Frequency of E7-specific CTLs in peptide-immunized mice. Mice were injected subcutaneously with $1 \times 10^{6} \mathrm{C} 3$ cells. Seven days later, tumor-bearing mice $(\mathbf{a})$ or naive mice $(\mathbf{b})$ were immunized intradermally on the contralateral flank with $50 \mu \mathrm{g}$ of E7 (aa 49-57) peptide emulsified in IFA (Sigma Chemical Co.). Ab's including the control rat $\mathrm{IgG}$ and $\mathrm{mAb} 2 \mathrm{~A}(100 \mu \mathrm{g})$ were given intraperitoneally in $0.5 \mathrm{ml}$ PBS on days 1 and 4 . Cells from two to three mice in each group were pooled. Seven days later, LN cells draining the site of immunization were stained with $\mathrm{H}-2 \mathrm{D}^{\mathrm{b}}-\mathrm{E} 7$ following in vitro restimulation with irradiated C3 cells, as previously described. (c) After the 4-day restimulation, cells from the draining $L N s$ of the naive mice immunized with E7 peptide and given control rat IgG (filled circles) or mAb $2 \mathrm{~A}$ (open circles) were used as effectors in a 4 -hour ${ }^{51} \mathrm{Cr}$ release assay against EL4 (left panel), E7 peptide-pulsed EL4 (middle panel), and C3 (right panel) targets at the indicated $\mathrm{E} / \mathrm{T}$ ratios. Data shown is representative of at least four experiments.

\section{Figure 4}

Frequency of E7-specific CTLs in the TDLNs of C3- and EL4E7bearing mice. TDLNs were harvested from tumor-bearing mice and restimulated in vitro as described in Figure 3 legend. After 4 days in culture, cells were double-stained with tetrameric $\mathrm{H}-2 \mathrm{D}^{\mathrm{b}}-\mathrm{E} 7$ or $\mathrm{H}-2 \mathrm{D}^{\mathrm{b}}-\mathrm{Vp} 2$ (aa 121-130) and anti-CD8. The percentage of total $\mathrm{CD}^{+}$cells that stained with the $\mathrm{H}-2 \mathrm{D}^{\mathrm{b}}-\mathrm{E} 7$ tetramer is shown (a). Viable $\mathrm{CD}^{+}$cells were gated, and the fraction of cells that stained with tetrameric $\mathrm{H}-2 \mathrm{D}^{\mathrm{b}}-\mathrm{E} 7$ ( aa 49-57) is shown. Data are presented as the average of three independent experiments (b). Background staining with the $\mathrm{H}-2 \mathrm{D}^{\mathrm{b}}-\mathrm{Vp} 2$ tetramer was subtracted from the original data.

detectable after immunization with control $\mathrm{Vp} 2$ peptide. Treatment with $\mathrm{mAb} 2 \mathrm{~A}$ resulted in a further increase in the frequency of E7-specific CTLs (Figure 5a). A similar result was obtained by immunization of naive mice (Figure $5 b$ ). In addition, E7-specific CTL activity against $\mathrm{C} 3$ cells could be detected by immunization with $\mathrm{E} 7$ peptide and further enhanced by $\mathrm{mAb}$ $2 \mathrm{~A}$ treatment (Figure $5 \mathrm{c}$ ). Our results indicate that E7specific CTLs are present in C3-bearing mice but are neither activated nor deleted. We conclude that E7-specific CTLs ignore antigens presented by the $\mathrm{C} 3$ tumor. In addition, anti-4-1BB mAb alone is unable to break this ignorant state.

Regression of established C3 tumor after breaking CTL ignorance with $E 7$ peptide and anti-4-1BB $m A b 2 A$. Because immunization by $\mathrm{E} 7$ peptide increases CTL frequency in C3-bearing mice, we tested whether this is an effective treatment for established C3 tumors. Mice bearing C3 tumors for 7 days were immunized with either E7 or the control Vp2 peptide. The mice were observed for at least 12 weeks following treatment and were sacrificed after the size of the tumor reached $15 \mathrm{~mm}$ in diameter. Tumor regression was observed in only one of 11 (9\%) mice treated with the E7 peptide. Therefore, E7 peptide immunization is not sufficient to treat
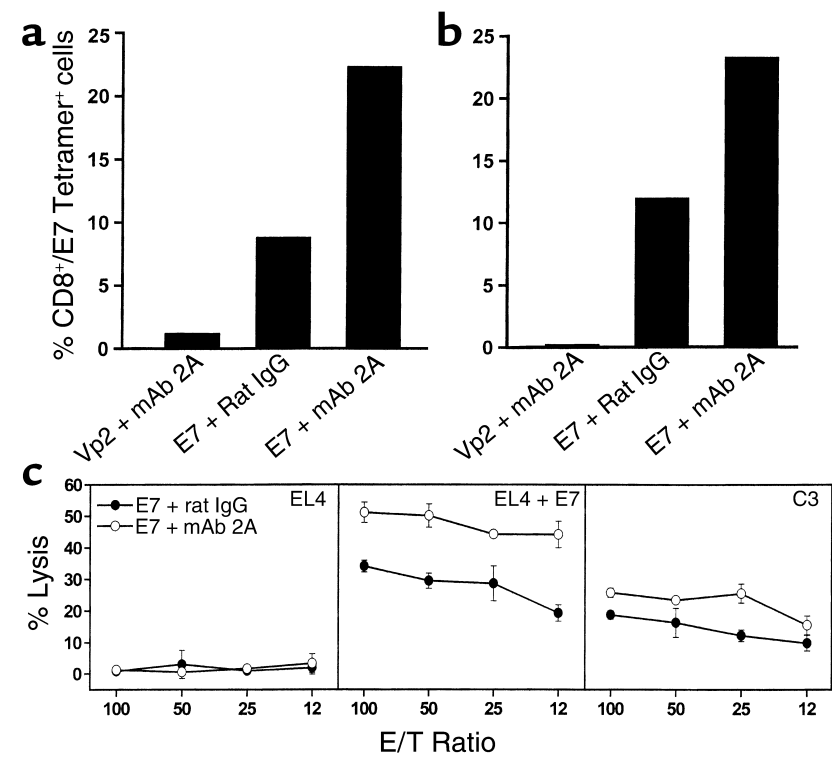


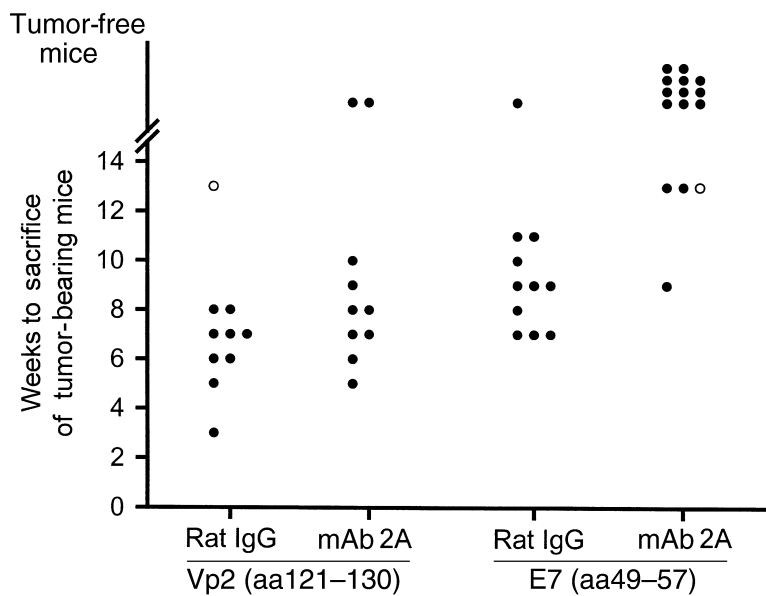

established C3 tumors. However, tumors regressed completely in 11 of $15(73 \%)$ mice that received costimulatory 4-1BB mAb plus E7 peptide (COPP) treatment. In contrast, two of ten $(20 \%)$ control mice treated with $\mathrm{mAb} 2 \mathrm{~A}$ plus the control $\mathrm{Vp} 2$ peptide were tumor-free. Tumors in the mice treated with the control Vp2 peptide and rat IgG reached $15 \mathrm{~mm}$ in diameter within 8 weeks, with the exception of a single mouse bearing a smaller tumor $(<15 \mathrm{~mm})$ for more than 12 weeks (Figure 6). In addition, those tumors that failed to regress in mice after COPP treatment grew more slowly than did tumors in the control groups (Figure 6). Therefore, COPP treatment effectively induced the regression of established $\mathrm{C} 3$ tumors.

We next determined whether COPP treatment is also effective in treating larger $\mathrm{C} 3$ tumors. As summarized in Table 1, mice bearing C 3 tumors for 14 days $(5-8 \mathrm{~mm}$ in diameter at the time of treatment) were treated by COPP. Tumor regression was observed in 16 of 38 (42\%) mice. In contrast, tumor regression was observed in $0 \%$, $9 \%$, and $0 \%$, respectively, of mice treated with E7 peptide, $\mathrm{mAb} 2 \mathrm{~A}$ alone, or the control rat IgG plus the $\mathrm{Vp} 2$ peptide. Tumors that failed to completely regress in the mice given COPP treatment were also significantly smaller 21 days after treatment than tumors observed in all three control groups of mice.

Effect of COPP treatment in mice depleted of $\mathrm{CD} 4^{+}$or $\mathrm{NK} 1.1^{+}$cells. In order to identify effector and immunoregulatory cells that are important in mediating the tumor regression observed after COPP treatment in C3-bearing mice, depleting mAb's were used to deplete mice of $\mathrm{CD} 4^{+}$cells or NK1.1 $1^{+}$cells. Tumor regression was observed after depletion of $\mathrm{CD} 4^{+} \mathrm{T}$ cells. In fact, tumors in CD4-depleted mice tended to regress more quickly than did those in the control mice, although this trend was not statistically significant (data not shown). Although depletion of NK1.1 $1^{+}$cells did not completely abrogate the therapeutic effect observed after COPP treatment,

\section{Figure 6}

Regression of established C3 tumors after treatment with the E7 peptide and $\mathrm{mAb} 2 \mathrm{~A}$. Mice were injected subcutaneously with $1 \times 10^{6} \mathrm{C} 3$ cells. Seven days later, mice were divided into two groups and were immunized intradermally with either $V p 2$ or E7 peptide ( $50 \mu \mathrm{g} /$ mouse) emulsified in IFA. On days 7 and 10 , mice received $100 \mu \mathrm{g}$ of the control rat IgG or mAb 2A intraperitoneally. Tumor size was assessed weekly for each mouse, and the mice were sacrificed at the times indicated, when the average tumor diameter reached $15 \mathrm{~mm}$ (filled circles). Mice bearing tumors less than an average of $15 \mathrm{~mm}$ in diameter were sacrificed upon termination of the experiment, at 13 weeks (open circles). Data was combined from two similarly performed experiments. The improved survival observed in the treatment group receiving both the E7 peptide and $\mathrm{mAb} 2 \mathrm{~A}$ was statistically significant, as determined by the $\chi^{2}$ test. $(P \leq 0.01)$.

only $42 \%$ of tumors regressed in these mice, compared with $86 \%$ in the nondepleted control mice. Our results indicate that NK1.1 $1^{+}$cells, but not $\mathrm{CD}^{+}$cells, participate in the therapeutic effect of COPP treatment.

Effect of COPP treatment in metastasis models of TC-1 lung cancer and B16-F10 melanoma. To determine the effect of COPP treatment in other poorly immunogenic tumors, two additional tumor models were tested. The TC-1 tumor line is derived from primary lung epithelial cells that have been cotransformed with the HPV-16 E6, HPV-16 E7, and ras oncogenes (22). Therefore, the E7 peptide could be used as an immunogen. B16-F10 is a highly metastatic melanoma line that presents a $\mathrm{H}-2 \mathrm{~K}^{\mathrm{b}}$-restricted TRP-2 peptide (23-25). B6 mice were given $1 \times 10^{4} \mathrm{TC}-1$ cells intravenously to establish lung metastases. Three days after tumor infusion, the mice were treated with the $\mathrm{E} 7$ peptide and $\mathrm{mAb} 2 \mathrm{~A}$. As was observed with the $\mathrm{C} 3$ tumor, the administration of $\mathrm{mAb} 2 \mathrm{~A}$ alone was insufficient to prolong survival in the tumor-bearing mice; all of the mice died within 20 days. E7 peptide immunization alone did prolong survival, although all of the mice were dead by day 35 . COPP treatment led to a significant survival advantage, such that all of the mice that had received both the E7 peptide and $\mathrm{mAb} 2 \mathrm{~A}$ survived at least 35 days. This is
Table 1

Treatment of mice bearing established C3 tumors

\begin{tabular}{lcccc}
\hline \multicolumn{2}{c}{$\begin{array}{c}\text { Treatment } \\
\mathrm{A}\end{array}$} & $\begin{array}{c}\text { Pumor-free/total } \\
\text { (\%) }\end{array}$ & $\begin{array}{c}\text { Mean tumor } \\
\text { diameter }(\mathrm{mm})^{\mathrm{B}}\end{array}$ & $P_{\text {value }}$ \\
2A & E7 (aa 49-57) & $16 / 38(42 \%)$ & $7.6 \pm 2.4$ & - \\
Rat IgG & E7 (aa 49-57) & $0 / 11(0 \%)$ & $10.5 \pm 3.0$ & 0.017 \\
2A & Vp2 (aa 121-130) & $2 / 23(9 \%)$ & $11.4 \pm 4.0$ & 0.004 \\
Rat IgG & Vp2 (aa 121-130) & $0 / 8(0 \%)$ & $11.5 \pm 3.5$ & 0.005
\end{tabular}

AMice were injected with $1 \times 10^{6} \mathrm{C} 3$ cells. Two weeks later, mice were immunized with the indicated peptide, as previously described. On the day of immunization and again 3 days later, mice were given $100 \mu \mathrm{g}$ of either mAb $2 \mathrm{~A}$ or a control rat IgG intraperitoneally. Tumor size was assessed weekly. Data shown were pooled from several experiments. BTwenty-one days after treatment, the mean tumor diameter was calculated for those tumors that had failed to completely regress. CThe unpaired Student $t$ test was used to calculate $P$ values, comparing the mean tumor diameter of the treatment group that received both the E7 peptide and $\mathrm{mAb} 2 \mathrm{~A}$ with that of the control group. 
Table 2

COPP treatment in mice depleted of $\mathrm{CD}^{+}$, and $\mathrm{NK} 1.1^{+}$cells

\begin{tabular}{lccc}
\hline Depleting mAb & Treatment $^{\mathrm{B}}$ & Tumor-free/total (\%) & $P$ value $^{\mathrm{C}}$ \\
- & None & $0 / 5(0 \%)$ & \\
Rat IgG & COPP & $18 / 21(86 \%)$ & \\
Anti-CD4 & COPP & $10 / 10(100 \%)$ & \\
Anti-NK1.1 & COPP & $8 / 19(42 \%)$ & $<0.02$
\end{tabular}

AMice were given $200 \mu \mathrm{g}$ of the indicated mAb prior to treatment and every 3-4 days thereafter. Depletion of the appropriate cell subset was verified by FACS analysis. ${ }^{B}$ Mice were injected with $1 \times 10^{6} \mathrm{C} 3$ cells. Seven days later, mice were either left untreated or immunized with E7 and given mAb 2A (COPP). Tumor size was assessed weekly. Data shown was pooled from three identical experiments. CThe unpaired Student $t$ test was used to calculate $P$ values comparing the rate of tumor regression in mice that were treated to deplete cell subsets with the regression rate in nondepleted mice that were given the rat IgG control Ab.

the time by which all of the mice in the control groups had died (Figure 7a). Twenty percent of the mice receiving both the $\mathrm{E} 7$ peptide and $\mathrm{mAb} 2 \mathrm{~A}$ were long-term survivors. In a second model, mice were given $1 \times 10^{5}$ B16-F10 cells intravenously and treated by COPP 3 days later. As before, treatment by either $\mathrm{mAb} 2 \mathrm{~A}$ or the TRP-2 peptide alone was ineffective. However, COPP treatment led to a significant survival advantage for all of the mice and to long-term survival (>90 days) in $20 \%$ of them. Therefore, combined treatment with an antigenic, MHC class I-restricted peptide and anti-4-1BB $\mathrm{mAb}$ (COPP treatment) may be therapeutic for established, poorly immunogenic tumors.

\section{Discussion}

We reported previously that the antitumor CTL response is enhanced by agonistic anti-4-1BB $\mathrm{mAb}$ administration, leading to the eradication of well-established P815 mastocytomas and AG104A sarcomas in syngeneic mice (15). In this study, we show that large established EL4E7 lymphomas could also be eradicated in mice given anti-4-1BB mAb $2 \mathrm{~A}$. However, treatment with anti-4-1BB $\mathrm{mAb}$ alone is not effective against the established C3 tumor. We demonstrate that CTLs against tumor antigens are neither activated nor deleted during progression of $\mathrm{C} 3$ tumors (i.e., tumor-specific CTLs are ignorant of tumor antigens). Immunological ignorance of specific CTLs appears to prevent anti-4-1BB mAb from activating tumor immunity, since anti-4-1BB $\mathrm{mAb}$ itself neither activates tumor-specific CTLs nor induces the regression of established C3 tumors. Similar observations were made in the TC-1 lung carcinoma and B16-F10 melanoma models.

The peaceful coexistence of antigen-specific $\mathrm{T}$ cells and their corresponding antigen in vivo is characteristic of immunological ignorance (33-36). In general, this phenomenon is considered a passive process, as ignorant $\mathrm{T}$ cells have a naive phenotype. However, immunilogical ignorance may be explained by expression levels of the ignored antigen or the anatomic site in which it is expressed $(37,38)$. Kim et al. recently reported that the poorly immunogenic MCA205 and
GL261 tumors, when grown subcutaneously or as pulmonary metastases, were resistant to anti-4-1BB mAb treatment (39). In contrast, the same tumors, when grown intracranially, responded to anti-4-1BB $\mathrm{mAb}$ therapy. This suggests that these tumors, although ignored in the periphery, were sufficiently immunogenic when located intracranially to prime a specific $\mathrm{T}$ cell response, a contention supported by the authors' observation that numerous OX- $40 \mathrm{R}^{+} \mathrm{T}$ cells infiltrated the intracranial tumors. This may explain the observation that both the intracranial and subcutaneous tumors responded to anti-4-1BB mAb therapy when both tumors were present.

Since $T$ cell activation requires two signals (one from the $T$ cell receptor and an additional costimulatory signal), ignorant $\mathrm{T}$ cells may not respond to some costimulatory signals. These signals could include our costimulatory anti-4-1BB mAb, as $\mathrm{T}$ cell receptor signaling is presumably a prerequisite for the subsequent upregulation of $4-1 \mathrm{BB}$ expression $(1,2)$. This may explain our observation that anti-4-1BB mAb itself is not effective in stimulating E7-specific CTLs in vivo in C3-bearing mice. It is unknown at this time why

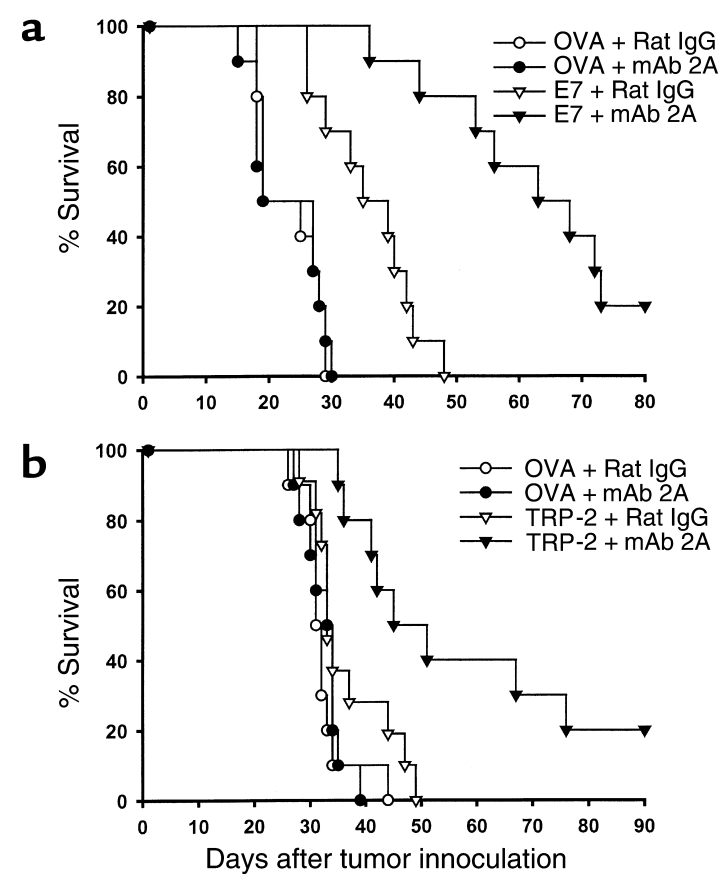

Figure 7

COPP treatment of established TC-1 and B16-F10 lung metastases. Mice were given $1 \times 10^{4} \mathrm{TC}-1$ cells $(\mathbf{a})$ or $1 \times 10^{5}$ B16-F10 cells $(\mathbf{b})$ intravenously and were immunized intradermally 3 days later with the OVA peptide (circles), the E7 peptide (triangles in a), or the trp- 2 peptide (triangles in $\mathbf{b}$ ). The peptides were emulsified in IFA and the mice were given $50 \mu \mathrm{g}$ of peptide at each of two immunization sites. On the day of immunization, and again 3 days later, the mice received $100 \mu \mathrm{g}$ of either rat IgG or mAb $2 \mathrm{~A}$ intraperitoneally. The mice were monitored daily for the duration of the experiment. Survival data from two identically performed experiments $(n=10)$ were combined. Mice treated with the E7 peptide (in a) or trp-2 peptide (in b) plus $\mathrm{mAb} 2 \mathrm{~A}$ had a significant survival advantage in all experiments performed, as determined by the log rank test $(P \leq 0.001)$. 
the E7 oncogene product in C3 cells is ignored by CTLs. Our group and others have found that $\mathrm{C} 3$ cells can be lysed in vitro by preactivated $\mathrm{CD}^{+} \mathrm{CTLs}$ that specifically recognize a $2-\mathrm{HD}^{\mathrm{b}}$-E7 epitope (see ref. 20 and Figure $3 \mathrm{c}$ ). It was also reported that the E7 oncogene is required for maintenance of the transformed phenotype $(40,41)$. Furthermore, our results demonstrate that appropriate activation of E7-specific CTLs by a combined E7-derived peptide and $\mathrm{mAb} 2 \mathrm{~A}$ can elicit high levels of E7-specific CTLs, leading to the complete regression of established C3 tumors in vivo. Our results thus exclude antigen loss as a primary reason for immunological ignorance in this system. It is possible that the $\mathrm{E} 7$ antigen is presented by $\mathrm{C} 3$ cells in such a way that the level of peptide-MHC complex is insufficient to surpass a minimal threshold of $\mathrm{T}$ cell receptor signaling required for $\mathrm{T}$ cell activation. In addition, C3 cells express significantly lower levels of MHC class I antigen than do EL4 cells (data not shown). This may explain why C3 cells are less sensitive to lysis than EL4 cells by activated CTLs (Figure 5c). Taken together, our results support an insufficient first signal in tumorbearing mice that prevents further costimulation by anti-4-1BB mAb.

Immunization with the E7-derived peptide appears to be capable of breaking the ignorant state of CTLs, as this immunization leads to the appearance of detectable CTLs in draining LNs, although this is not sufficient to treat established tumors. Immunization of naive mice with the peptide, however, can prevent the outgrowth of $\mathrm{C} 3$ tumors following a subsequent tumor challenge (ref. 20 and Wilcox et al., unpublished data). Similarly, growth of an EL4E7 lymphoma elicits a CTL response in tumor-bearing mice, although this response is incapable of controlling tumor growth (Figure 2 and Figure 3), and further costimulation by anti-4-1BB mAb is required for tumor eradication. Therefore, breaking $\mathrm{T}$ cell ignorance by $\mathrm{E} 7$ peptide immunization is necessary, but not sufficient, to successfully treat established C3 tumors. The efficacy of either anti-4-1BB mAb alone or administered in combination with E7 peptide is often less than $100 \%$, leaving room for further improvement. In addition to tumor cell heterogeneity, tumor escape mechanisms, including loss of either MHC class I or tumorassociated antigens, may play a role. Nevertheless, our results highlight the importance of evaluating the status of $\mathrm{T}$ cells in animal models and in cancer patients in order to design better therapeutic strategies. For example, it has been shown that anergy to tumor antigens may prevent the generation of tumor immunity in several mouse tumor models and possibly in human cancers (42-44). It is well known that a cancer cell may express multiple antigens, many serving as potential targets for a $\mathrm{T}$ cell response $(33,45)$. In such cases, an immunotherapeutic strategy should include the selection of immunogenic antigens to which $\mathrm{T}$ cells are not anergic, in the hope of achieving further costimulatory enhancement.
The mechanisms of anti-4-1BB mAb in enhancing tumor immunity remain to be fully elucidated. Costimulation of $\mathrm{T}$ cell immunity in vivo may explain this effect, at least in part. However, the role of $4-1 \mathrm{BB}$ in $\mathrm{T}$ cell immunity may be more complicated than previously thought. For example, several recent studies indicate that anti-4-1BB mAb inhibits $\mathrm{T}$ cell apoptosis in vivo and may thus prolong the CTL response $(10,11)$. We have found recently that administration of anti-IFN- $\boldsymbol{\gamma} \mathrm{mAb}$ can largely abrogate the effect of COPP treatment (Wilcox et al., unpublished data), suggesting that IFN- $\gamma$ may also be an important effector molecule involved in tumor regression following treatment. We have previously demonstrated in a P815 tumor model that both $\mathrm{CD} 4^{+} \mathrm{T}$ cells and NK1.1 ${ }^{+}$cells express $4-1 \mathrm{BB}$ and are required for anti-4-1BB $\mathrm{mAb}$ to induce anti-tumor immune response $(8,15)$. In the $\mathrm{C} 3$ tumor system, although $\mathrm{CD}^{+} \mathrm{T}$ cells were not required for the therapeutic effect observed after COPP treatment, the effect was dependent upon NK1.1 $1^{+}$cells, at least in part (Table 2). Our findings indicate that the effect of COPP treatment is not only mediated by activated $\mathrm{T}$ cells, but may also involve cross-talk with other cell subsets, including NK cells. Our observation that poorly immunogenic tumors such as the $\mathrm{C} 3$ tumor, TC-1 lung carcinoma, and B16-F10 melanoma may completely regress in some of the mice is encouraging. However, this treatment is effective in only a fraction of the mice bearing large tumors and may require further optimization. Nevertheless, our results suggest that a combined, two signal-based $\mathrm{T}$ cell activation strategy may be effective in the treatment of human cancers.

\section{Acknowledgments}

We thank W. Martin Kast, Germain Fernando, T.C. Wu, and Glenn Dranoff for the C3, EL4E7, TC-1, and B16-F10 tumor lines. We also thank Julie Lau for technical assistance and Kathy Jensen for editing the manuscript. This study is supported by grants from the Cancer Research Institute (New York, New York, USA), NIH (CA-79915 and CA-85721), and the National Natural Science Foundation of China (to L. Chen), by NIH postdoctoral training grant CA-09127 (to G. Zhu and A.I. Chapoval), and by the US Army Medical Research and Materiel Command postdoctoral fellowship (to K. Tamada).

\footnotetext{
1. Sica, G., and Chen, L. 2000. Modulation of the immune response through 4-1BB. Adv. Exp. Med. Biol. 465:355-362.

2. Vinay, D.S., and Kwon, B.S. 1998. Role of 4-1BB in immune responses. Semin. Immunol. 10:481-489.

3. Pollok, K.E., et al. 1993. Inducible T cell antigen 4-1BB. Analysis of expression and function. J. Immunol. 150:771-781.

4. DeBenedette, M.A., Shahinian, A., Mak, T.W., and Watts, T.H. 1997. Costimulation of CD28- T lymphocytes by 4-1BB ligand. J. Immunol. 158:551-559.

5. Saoulli, K., et al. 1998. CD28-independent, TRAF2-dependent costimulation of resting T cells by 4-1BB ligand. J. Exp. Med. 187:1849-1862.

6. Cannons, J.L., Choi, Y., and Watts, T.H. 2000. Role of TNF receptor-associated factor 2 and p38 mitogen-activated protein kinase activation during 4-1BB-dependent immune response. J. Immunol. 165:6193-6204.

7. Cannons, J.L., Hoeflich, K.P., Woodgett, J.R., and Watts, T.H. 1999. Role of the stress kinase pathway in signaling via the $\mathrm{T}$ cell costimulatory receptor 4-1BB. J. Immunol. 163:2990-2998.
} 
8. Melero, I., Johnston, J.V., Shufford, W.W., Mittler, R.S., and Chen, L. 1998. NK1.1 cells express 4-1BB (CDw137) costimulatory molecule and are required for tumor immunity elicited by anti-4-1BB monoclonal antibodies. Cell. Immunol. 190:167-172.

9. Kienzle, G., and Kempis, J. 2000. CD137 (ILA/4-1BB), expressed by primary human monocytes, induces monocyte activation and apoptosis of B lymphocytes. Int. Immunol. 12:73-82.

10. Hurtado, J.C., Kim, Y.J., and Kwon, B.S. 1997. Signals through 4-1BB are costimulatory to previously activated splenic T cells and inhibit activation-induced cell death. J. Immunol. 158:2600-2609.

11. Takahashi, C., Mittler, R.S., and Vella, A.T. 1999. 4-1BB is a bona fide CD8 T cell survival signal. J. Immunol. 162:5037-5040.

12. Tan, J.T., Whitmire, J.K., Ahmed, R., Pearson, T.C., and Larsen, C.P. 1999. 4-1BB ligand, a member of the TNF family, is important for the generation of antiviral CD8 T cell responses. J. Immunol. 163:4859-4868.

13. DeBenedette, M.A., et al. 1999. Analysis of 4-1BB ligand (4-1BBL)-deficient mice and of mice lacking both 4-1BBL and CD28 reveals a role for $4-1 \mathrm{BBL}$ in skin allograft rejection and in the cytotoxic $\mathrm{T}$ cell response to influenza virus. J. Immunol. 163:4833-4841.

14. Tan, J.T., et al. 2000. 4-1BB costimulation is required for protective antiviral immunity after peptide vaccination. J. Immunol. 164:2320-2325.

15. Melero, I., et al. 1997. Monoclonal antibodies against the 4-1BB T-cell activation molecule eradicate established tumors. Nat. Med. 3:682-685.

16. Guinn, B.A., DeBenedette, M.A., Watts, T.H., and Berinstein, N.L. 1999. 4-1BBL cooperates with B7-1 and B7-2 in converting a B cell lymphoma cell line into a long-lasting antitumor vaccine. J. Immunol. 162:5003-5010.

17. Melero, I., et al. 1998. Amplification of tumor immunity by gene transfer of the co-stimulatory 4-1BB ligand: synergy with the CD28 co-stimulatory pathway. Eur. J. Immunol. 28:1116-1121.

18. Martinet, O., et al. 2000. Immunomodulatory gene therapy with interleukin 12 and 4-1BB ligand: long-term remission of liver metastases in a mouse model. J. Natl. Cancer Inst. 92:931-936.

19. Chen, S.H., et al. 2000. Rejection of disseminated metastases of colon carcinoma by synergism of IL-12 gene therapy and 4-1BB costimulation. Mol. Ther. 2:39-46.

20. Feltkamp, M.C., et al. 1993. Vaccination with cytotoxic T lymphocyte epitope-containing peptide protects against a tumor induced by human papillomavirus type 16-transformed cells. Eur. J. Immunol. 23:2242-2249.

21. Tindle, R.W., et al. 1995. A vaccine conjugate of 'ISCAR' immunocarrier and peptide epitopes of the E7 cervical cancer-associated protein of human papillomavirus type 16 elicits specific Th1- and Th2-type responses in immunized mice in the absence of oil-based adjuvants. Clin. Exp. Immunol. 101:265-271.

22. Lin, K.Y., et al. 1996. Treatment of established tumors with a novel vaccine that enhances major histocompatibility class II presentation of tumor antigen. Cancer Res. 56:21-26.

23. Dranoff, G., et al. 1993. Vaccination with irradiated tumor cells engineered to secrete murine granulocyte-macrophage colony-stimulating factor stimulates potent, specific, and long-lasting anti-tumor immunity. Proc. Natl. Acad. Sci. USA. 90:3539-3543.

24. Bloom, M.B., et al. 1997. Identification of tyrosinase-related protein 2 as a tumor rejection antigen for the B16 melanoma. J. Exp. Med. 185:453-459.

25. Schreurs, M.W.J., et al. 2000. Dendritic cells break tolerance and induce protective immunity against a melanocyte differentiation antigen in an autologous melanoma model. Cancer Res. 60:6995-7001.

26. Johnson, A.J., et al. 1999. Prevalent class I-restricted T-cell response to the Theiler's virus epitope $\mathrm{D}^{\mathrm{b}}: \mathrm{V} \mathrm{p} 2121-130$ in the absence of endogenous CD4 help, tumor necrosis factor alpha, gamma interferon, perforin, or costimulation through CD28. J. Virol. 73:3702-3708.

27. Curtsinger, J.M., Lin, D.C., and Mescher, M.F. 1998. CD8 ${ }^{+}$memory T cells $\left(\mathrm{CD} 44^{\text {high }}, \mathrm{Ly}-6 \mathrm{C}^{+}\right)$are more sensitive than naive cells to (CD44low, Ly-6C-) to TCR/CD8 signaling in response to antigen. J. Immunol. 160:3236-3243

28. Moore, M., Carbone, F., and Bevan, M. 1988. Introduction of soluble protein into the class I pathway of antigen processing and presentation. Cell. 54:777-785.

29. Tamada, K., et al. 2000. Modulation of T-cell-mediated immunity in tumor and graft-versus-host disease models through the LIGHT costimulatory pathway. Nat. Med. 6:283-289.

30. Chapoval, A.I., Zhu, G., and Chen, L. 2000. Immunoglobulin fusion proteins as a tool for evaluation of T-cell costimulatory molecules. Methods Mol. Med. 45:247-256.

31. Shuford, W.F., et al. 1997. 4-1BB costimulatory signals preferentially induce $\mathrm{CD}^{+} \mathrm{T}$ cell proliferation and lead to the amplification in vivo of cytotoxic T cell responses. J. Exp. Med. 186:47-55.

32. Van Hall, T., et al. 2000. Identification of a novel tumor-specific CTL epitope presented by RMA, EL-4, and MBL-2 lymphomas reveals their common origin. J. Immunol. 165:869-877.

33. Chen, L. 1998. Immunological ignorance of silent antigens as an explanation of tumor evasion. Immunol. Today. 19:338-341.

34. Ochsenbein, A.F., et al. 1999. Immune surveillance against a solid tumor fails because of immunological ignorance. Proc. Natl. Acad. Sci. USA. 96:2233-2238.

35. Wick, M., et al. 1997. Antigenic cancer cells grow progressively in immune hosts without evidence for $\mathrm{T}$ cell exhaustion or systemic anergy. J. Exp. Med. 186:229-238.

36. Hermans, I.F., Daish, A., Yang, J., Ritchie, D.S., and Ronchese, F. 1998. Antigen expressed on tumor cells fails to elicit an immune response, even in the presence of increased numbers of tumor-specific cytotoxic T lymphocyte precursors. Cancer Res. 58:3909-3917.

37. Kurts, C., et al. 1999. CD8 T cell ignorance or tolerance to islet antigens depends on antigen dose. Proc. Natl. Acad. Sci. USA. 96:12703-12707.

38. Melero, I., et al. 1997. Immunological ignorance of an E7-induced cytolytic T-lymphocyte epitope in transgenic mice expressing the E7 and E6 oncogenes of human papillomavirus type 16. J. Virol. 71:3998-4004.

39. Kim, J., et al. 2001. Divergent effects of 4-1BB antibodies on antitumor immunity and on tumor-reactive T-cell generation. Cancer Res. 61:2031-2037.

40. zur Hausen, H. 1999. Immortalization of human cells and their malignant conversion by high risk human papillomavirus genotypes. Semin. Cancer Biol. 9:405-411.

41. zur Hausen, H. 1996. Papillomavirus infections-a major cause of human cancers. Biochem. Biophys. Acta. 1288:F55-F78.

42. Finke, J., Ferrone, S., Frey, A., Mufson, A., and Ochoa, A. 1999. Where have all the $\mathrm{T}$ cells gone? Mechanisms of immune evasion by tumors. Immunol. Today. 20:158-160.

43. Staveley-O'Carroll, K., et al. 1998. Induction of antigen-specific T cell anergy: an early event in the course of tumor progression. Proc. Natl. Acad. Sci. USA. 95:1178-1183.

44. Reilly, R.T., et al. 2000. HER-2/neu is a tumor rejection target in tolerized HER-2/neu transgenic mice. Cancer Res. 60:3569-3576.

45. Johnston, J.V., et al. 1996. B7-CD28 costimulation unveils the hierarchy of tumor epitopes recognized by major histocompatibility complex class I-restricted CD8 ${ }^{+}$cytolytic T lymphocytes. J. Exp. Med. 183:791-800. 